\title{
Application of Fuzzy Based VIKOR Approach for Multi-Attribute Group Decision Making (MAGDM): A Case Study in Supplier Selection
}

\author{
Chitrasen Samantra*, Saurav Datta*, Siba Sankar Mahapatra
}

\begin{abstract}
In today's competitive global markets, selection of a potential supplier plays an important role to cut production costs as well as material costs of the company. This leads to successful survival and sustainability in a competitive marketplace. Therefore, evaluation and selection of an appropriate supplier has become an important part of supply chain management. The nature of the supplier selection process is a complex multi-attribute group decision making (MAGDM) problem which deals with both quantitative and qualitative factors may be conflicting in nature as well as contain incomplete and uncertain information. In order to solve such a kind of MAGDM problems, the development of an effective supplier selection model is evidently desirable. In this paper, an application of the VIKOR method combined with fuzzy logic has been used to solve supplier selection problems with confliting and non-commensurable (different units) criteria, assuming that compromising is acceptable for conflict resolution. The decision maker wants a solution, which must be closest to the ideal, and the alternatives are evaluated according to all established criteria. Linguistic values are used to assess the ratings and weights for the conflicting factors. These linguistic ratings can be expressed in triangular fuzzy numbers. Then, a hierarchy MAGDM model based on fuzzy sets theory and the VIKOR method has been proposed to deal with the supplier selection problems in the supply chain system. A case study has been illustrated as an application of the proposed model.
\end{abstract}

Keywords: Supplier selection; MAGDM, Fuzzy set theory; VIKOR method

Mathematics Subject Classification: 62C86 - Decision theory and fuzziness, 90B50 - Management decision making, 90B06 - Transportation, logistics

Revised: May 28, 2012

\section{INTRODUCTION}

In today's' competitive business scenario, supplier selection has become a major concern for every organizations. Supplier selection requires a wide conceptual and experimental framework to be carried out by the purchasing managers in a supply chain

\footnotetext{
* Department of Mechanical Engineering; National Institute of Technology, Rourkela-769008; E-mail: \{chitramech4u, sdattaju, mahaptrass2003\}@gmail.com; Communicating author: sdattaju@gmail.com
} 
management. Therefore, it is considered to be one of the most important responsibilities in the philosophy of any organizational purchase management. In literature survey, an extensive work was found to be made by previous researchers in the area of supplier selection and they have solved a variety of supplier selection problems using different multi-criteria decision making (MCDM) methods like Performance Value Analysis (PVA), Analytical Hierarchy Process (AHP), Analytical Network Process (ANP), Fuzzy logic, and TOPSIS approach. Apart from this, some hybrid and innovative approaches such as AHP-LP, ANP-TOPSIS and fuzzy-QFD are also being used to find a more precise decision towards the selection of a best alternative supplier from among a set of feasible alternatives.

But, this is still limited to an extent because as there are many multi-attribute group decision making (MAGDM) methods which may yield very different results when they are applied on exactly the same data. MAGDM problems are one of the important phases of the multi-criteria decision making (MCDM) process in which three or more decision makers have been grouped together for ranking and selecting the best alternative in the decision making process. The literature depicts some extensive work has been made in the MCDM area as follows.

Roodhooft and Konings (1996) proposed an Activity Based Costing (ABC) approach for vendor selection and evaluation. This system helped to compute the total cost caused by the supplier in the production process, thereby increasing the objectivity in the selection process. Weber et al. (1998) developed a theory and methodology of non-cooperative negotiation strategies for vendor selection. Ghodsypour and ÓBrien (1998) proposed an integration of the Analytical Hierarchy Process and Linear Programming (AHP-LP) to consider both tangible and intangible factors in selecting the best vendor. Altinoz and Winchester (2001) focused on the implementation of rulebased supplier selection methodology using fuzzy logic concepts. Tsai et al. (2003) applied grey relational analysis to the vendor selection model. Overall performance for each candidate vendor was evaluated; based on that, an optimum decision was taken. Kumar et al. (2004) developed a fuzzy goal programming approach to deal with the effect of vagueness and imprecision statement in the objectives of the vendor selection process and also highlighted how the quota allocation of vendors was changed with the uncertainty.

Saghafian and Hejazi (2005) presented a modified Fuzzy TOPSIS Technique (Order Performance by Similarity to Ideal Solution) for the Multi-Criteria Decision Making (MCDM) problem when there was a group of decision makers. Kubat and Yuce (2006) applied an integrated Fuzzy AHP and Genetic Algorithm (GA) approach to select the best supplier among the set of multiple suppliers deals with both subjective and objective criteria. Bashiri and Badri (2011) presented a new group decision making tool when decision data were not crisp and the decision maker wanted to rank the alternatives during the fuzzy interactive linear programming process. Because of the existence of linguistic terms in the decision matrix and the weight of each criterion which could be expressed in trapezoidal fuzzy numbers; an interactive method was proposed for ranking an alternative with the best weight for each criterion. Sanayei (2008) proposed an integrated approach of the multi-attribute utility theory (MAUT) and linear programming (LP) for rating and choosing the best suppliers and defining 
the optimum order quantities among selected ones in order to maximize total additive utility. Shahanaghi and Yazdian (2009) proposed the fuzzy group TOPSIS approach to make more realistic decisions for vendor selection in a fuzzy multi-criteria decision making environment.

From the literature review, it has been observed that, choosing a suitable and efficient methodology to solve a multi-criteria decision making problem and selecting the best alternative is a great challenge to researchers as well as management practitioners due to the existence of conflicting and non-commensurable criteria associated with the supplier selection problem. The selection is based on a group of decision making processes which is involved with uncertainty and imperfect information processing to some extent, such as randomicity and fuzzy (Wu and Liu, 2011).

In order to tackle this kind of uncertainty in the decision-making process, in the present work, a fuzzy based VIKOR approach has been attempted to evaluate the best supplier under multi- criteria decision making situations. The concept of fuzzy set theory has been applied in this paper to express decision-makers viewpoint in linguistic terms to overcome uncertainty on the estimation of qualitative factors. Linguistic judgment has been transformed to a corresponding fuzzy number. Then, a hierarchy MCDM model based on fuzzy sets theory and VIKOR has been used to deal with a supplier selection problem. The VIKOR method, a recently introduced new MCDM method developed to solve multiple criteria decision making (MCDM) problems with conflicting and non-commensurable criteria, may provide the basis for developing supplier selection models that can effectively deal with the characteristics of this problem (Opricovic, 1998).

Opricovic and Tzeng (2004) conducted a comparative analysis of VIKOR and TOPSIS, based on an aggregating function representing closeness to the reference point and provide the compromise solution by MCDM methods. Huang et al., (2009) developed a VIKOR model for MCDM which was used to determine the preference ranking from a set of alternatives in the presence of conflicting criteria. Chang (2010) proposed a modified VIKOR method to solve multiple criteria decision making (MCDM) problems with contradicting and non-commensurable criteria. Moeinzadeh and Hajfathaliha (2010) presented a supply chain risk assessment approach based on the analytic network process (ANP) and VIKOR method under the fuzzy environment where vagueness and subjectivity were handled with linguistic terms parameterized by triangular fuzzy numbers. Sanayei et al. (2010) studied a group decision making process for supplier selection with the VIKOR method under a fuzzy environment.

They selected a most suitable supplier, out of a set of five suppliers associated with multi-conflicting criteria and the evaluation process was carried out using trapezoidal fuzzy membership functions. Kuo and Liang (2011) proposed an effective approach by combining VIKOR with GRA techniques for evaluating the service quality of Northeast-Asian international airports by conducting customer surveys under fuzzy environment. This model was solved by an effective algorithm, which incorporated the decision-makers attitude and/or preference for customers' assessments on the weights and performance ratings of each criterion. 


\section{INTRODUCTION TO VIKOR METHOD}

The Serbian name VIKOR stands for 'VlseKriterijumska Optimizacija I Kompromisno Resenje', means multi-criteria optimization and compromise solution was developed by Opricovic in last 1998 (Opricovic and Tzeng 2004). This method concentrates on ranking and selecting the best from a set of alternatives, which are associated with multi-conflicting criteria. Moreover, it makes it easy for the decision makers to reach the final decision by finding the compromise solution (closest to the ideal) of a problem. The basic principle of VIKOR is determining the positive-ideal solution as well as the negative-ideal solution in the first place (Wu and Liu, 2011). The positiveideal solution is the best value of alternatives under the measurement criteria, and the negative -ideal solution is the worst value of alternatives under measurement criteria. In the end, arrange the precedence of the schemes based on the closeness of the alternatives assessed value to the ideal scheme. Therefore, the VIKOR method is popularly known as a multi-criteria decision making method based on the ideal point technique (Opricovic and Tzeng 2007).

For compromise ranking of multi-criteria measurement, VIKOR adopted a following form of LP-metric aggregate function (Yu, 1973):

$$
L_{P i}=\left\{\sum_{j=1}^{n}\left[w_{j}\left(f_{j}^{*}-f_{i j}\right) /\left(f_{j}^{*}-f_{j}^{-}\right)^{P}\right]\right\}^{1 / P},
$$

Here, $1 \leqslant P \leqslant \infty ; j=1, \ldots, n$, with respect to criteria and the variable $i=1, \ldots, m$, represent the number of alternatives such as $A_{1}, A_{2}, \ldots . A_{m}$. For alternative $A_{i}$, the evaluated value of the $j$ th criterion is denoted by $f_{i j}$, and $n$ is the number of criteria. The measure $L_{P i}$ shows the distance between alternative $A_{i}$ and the positive-ideal solution. Within the VIKOR method $L_{1 i}$ (as $S_{i}$ in Eq. (4)) and $L_{\infty i}$ (as $R_{i}$ in Eq. (5)) has been used to formulate the ranking measure. The value obtained by minimum $S_{i}$ is with a maximum group utility ('majority' rule) and the solution obtained by minimum $R_{i}$ is with a minimum individual regret of the 'opponent' (Sanayei et al. 2010). Then, the compromise ranking algorithm of the traditional VIKOR method has the following steps (Chang, 2010):

Step 1. Compute the positive-ideal solutions (best) value $f_{j}^{*}$ and negative-ideal solutions (worst) value $f_{j}^{-}$for all criterion ratings.

$$
\begin{gathered}
f_{j}^{*}= \begin{cases}\max _{i=1, \ldots, m} f_{i j}, & j \in C_{1} \\
\min _{i=1, \ldots, m} f_{i j,} & J \in C_{2}\end{cases} \\
f_{j}^{-}= \begin{cases}\min _{i=1, \ldots, m} f_{i j}, & j \in C_{1} \\
\max _{i=1, \ldots, m} f_{i j,} & J \in C_{2}\end{cases}
\end{gathered}
$$

Here, $j=1, \ldots, n$ and $\mathrm{C}_{1}$ is a benefit type criteria set, $\mathrm{C}_{2}$ is a cost type criteria set. 
Step 2. Compute the values of $\mathrm{S}_{i}$ and $\mathrm{R}_{i}(i=1, \ldots, m)$, by using the relations:

$$
\begin{gathered}
S_{i}=\sum_{j=1}^{n} w_{j}\left(f_{j}^{*}-f_{i j}\right) /\left(f_{j}^{*}-f_{j}^{-}\right), \\
R_{i}=\max _{j=1, \ldots, n}\left[w_{j}\left(f_{j}^{*}-f_{i j}\right) /\left(f_{j}^{*}-f_{j}^{-}\right)\right] .
\end{gathered}
$$

Here, $S_{i}$ is the aggregated value of $i^{\text {th }}$ alternatives with a maximum group utility and $R_{i}$ is the aggregated value of $i^{\text {th }}$ alternatives with a minimum individual regret of 'opponent'. $w_{j}$ is the fuzzy weighted average of each criterion.

Step 3. Compute the values $Q_{i}$ for $i=1, \ldots, m$ with the relation,

$$
Q_{i}=\nu\left(S_{i}-S^{*}\right) /\left(S^{-}-S^{*}\right)+(1-\nu)\left(R_{i}-R^{*}\right) /\left(R^{-}-R^{*}\right)
$$

Here, $S^{*}=\min _{i=1, \ldots, m} S_{i}, S^{-}=\max _{i=1, \ldots, m} S_{i}, R^{*}=\min _{i=1, \ldots, m} R_{i}, R^{-}=\max _{i=1, \ldots, m} R_{i}$ and $\nu$ is a weight for the strategy of maximum group utility, and $\nu=0.5$ where as $1-\nu$ is the weight of individual regret. The compromise can be selected with 'voting by majority' $(\nu>0.5)$, with 'consensus' $(\nu=0.5)$, with 'veto' $(\nu<0.5)$.

Step 4. Rank the alternatives by sorting each $S, R$, and $Q$ values in ascending order.

Step 5. If the following two conditions are satisfied simultaneously, then the scheme with minimum value of $\mathrm{Q}$ in ranking is considered the optimal compromise solution. Such as,

C1. The alternative $Q\left(A^{(1)}\right)$ has an acceptable advantage; in other words,

$$
Q\left(A^{(2)}\right)-Q\left(A^{(1)}\right) \geqslant 1 /(m-1) .
$$

Where, $A^{(2)}$ is the alternative with the second position in the ranking list by and $m$ is the number of alternatives.

C2. The alternative $Q\left(A^{(1)}\right)$ is stable within the decision making process; in other words, it is also best ranked in $S_{i}$ and $R_{i}$.

If condition $\mathrm{C} 1$ is not satisfied, that means $Q\left(A^{(m)}\right)-Q\left(A^{(1)}\right)<1 /(m-1)$, then alternatives $A^{(1)}, A^{(2)} \ldots A^{(m)}$ all are the same compromise solution, there is no comparative advantage of $A^{(1)}$ from others. But for the case of maximum value, the corresponding alternative is the compromise (closeness) solution. If condition $\mathrm{C} 2$ is not satisfied, the stability in decision making is deficient while $A^{(1)}$ has a comparative advantage. Therefore, $A^{(1)}$ and $A^{(2)}$ has the same compromise solution.

Step 6. Select the best alternative by choosing $Q\left(A^{(m)}\right)$ as a best compromise solution with the minimum value of $Q_{i}$ and must have to satisfy with the above conditions (Park et al. 2011). 


\section{ELEMENTS OF FUZZY SET THEORY}

Usually, it is very difficult to solve the problems due to the involvement of the subjectivity and uncertainty situation in the multi-criteria decision making process. Moreover, decision makers are frequently faced with confusions, and difficulties while dealing with this kind of decision making process. To overcome this vagueness, ambiguity and subjectivity of the human judgment process, fuzzy set theory has been introduced (Zadeh, 1965). Decision makers express their opinions in terms of linguistic scales. Linguistic data's are converted into fuzzy numbers with the help of different membership functions. Then, it becomes easy to solve multi-criteria decision making problems. Therefore, fuzzy set theory has become a helpful tool for mechanizing human activities with uncertainty-based information. This theory is incorporated with a paper because vagueness kind information related parameters present in this supplier selection problem.

Fuzzy number: Fuzzy numbers are a fuzzy subset of real numbers, and represent the expansion of the idea of a confidence interval (Zadeh, 1965). Let $A$ be the classical set of objects (e.g. universe), whose elements are denoted by $X$. The crisp value of a statement can be given by the membership function as $\mu_{A}$ from $X$ to $\{0,1\}$,

$$
\mu_{A}(X)= \begin{cases}1, & \text { if } X \in A, \\ 0, & \text { otherwise }\end{cases}
$$

Here, $\{0,1\}$ is called an evaluation set and it is permitted to be a real interval $[0,1]$ for the continuous mapping membership function. $\tilde{A}$ is called a fuzzy set and the function value $\mu_{\tilde{A}}(X)$ is termed as the degree of membership of $X$ in $\tilde{A}$. Fuzzy membership function has more types. But, in this paper a triangular fuzzy membership function has been used as shown in Figure 1 and the triangular fuzzy number, $\tilde{A}=(a, b, c)$ can be defined as:

$$
\mu_{\tilde{A}}(X)=\left\{\begin{array}{cc}
(x-a) /(b-a), & \text { if } \quad a \leqslant x \leqslant b, \\
(c-x) /(c-b), & \text { if } \quad b \leqslant x \leqslant c, \\
0, & \text { otherwise }
\end{array}\right.
$$

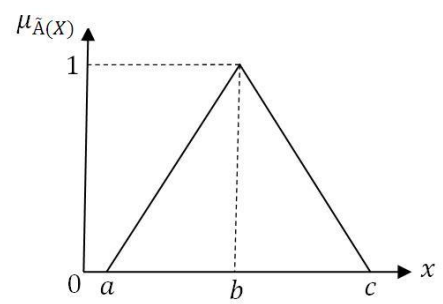

Fig. 1. Membership function of the triangular fuzzy number.

Based on the extension principle, the fuzzy sum $\oplus$ and fuzzy subtraction $\Theta$ of any two triangular fuzzy numbers are also triangular fuzzy numbers; but the multiplication $\otimes$ of any two triangular fuzzy numbers is only an approximate triangular 
fuzzy number (Zadeh, 1975). Let's have a two positive triangular fuzzy numbers, such as $\tilde{A}_{1}=\left(a_{1}, b_{1}, c_{1}\right)$, and $\tilde{A}_{2}=\left(a_{2}, b_{2}, c_{2}\right)$, and a positive real number $r=(r, r, r)$, some algebraic operations can be expressed as follows:

$$
\begin{aligned}
\tilde{A}_{1} \oplus \tilde{A}_{2} & =\left(a_{1}+a_{2}, b_{1}+b_{2}, c_{1}+c_{2}\right), \\
\tilde{A}_{1} \Theta \tilde{A}_{2} & =\left(a_{1}-a_{2}, b_{1}-b_{2}, c_{1}-c_{2}\right) \\
\tilde{A}_{1} \otimes \tilde{A}_{2} & =\left(a_{1} a_{2}, b_{1} b_{2}, c_{1} c_{2}\right), \\
r \otimes \tilde{A}_{1} & =\left(r a_{1}, r b_{1}, r c_{1}\right), \\
\tilde{A}_{1} \varnothing \tilde{A}_{2} & =\left(a_{1} / c_{2}, b_{1} / b_{2}, c_{1} / a_{2}\right) .
\end{aligned}
$$

The operations of $\vee(\max )$ and $\wedge(\min )$ are defined as:

$$
\begin{aligned}
& \tilde{A}_{1}(\vee) \tilde{A}_{2}=\left(a_{1} \vee a_{2}, b_{1} \vee b_{2}, c_{1} \vee c_{2}\right), \\
& \tilde{A}_{1}(\wedge) \tilde{A}_{2}=\left(a_{1} \wedge a_{2}, b_{1} \wedge b_{2}, c_{1} \wedge c_{2}\right),
\end{aligned}
$$

Here, $r>0$, and $a_{1}, b_{1}, c_{1}>0$,

Also, the crisp value of a triangular fuzzy number set $A_{1}$ can be determined by defuzzification which locates the Best Non-fuzzy Performance (BNP) value. Thus, the BNP values of a fuzzy number are calculated by using the center of area (COA) method as follows: (Moeinzadeh and Hajfathaliha, 2010)

$$
\mathrm{BNP}_{i}=\frac{[(c-a)+(b-a)]}{3}+a, \quad \forall i
$$

\section{METHODOLOGY ADOPTED}

Based on the concept of fuzzy set theory and VIKOR method, the proposed fuzzy VIKOR method has been applied to find the best compromise solution under the multi-person multi-criteria decision making supplier selection problem. Usually, decision making problems are dealing with some alternatives which can be ranked, with respect to distinct criteria. Ratings of the alternatives and the weights of each criterion are the two most significant data which can affect the results of decision making problems. Therefore, the proposed methodology has been used here, to calculate the definite weight of criteria and ranking of the alternatives. In this paper, the importance weights of various criteria and ratings of qualitative criteria are measured as linguistic variables because linguistic assessment can only have the capability to approximate the subjective judgment through a decision maker's opinion. Moreover, linear triangular membership functions are considered for capturing the vagueness of these linguistic assessments. The proposed algorithm consists of the following steps:

Step 1. Make a list of feasible alternatives, find the evaluation criteria, and constitute a group of decision makers. Suppose, there are $k$ decision makers $\left(D_{t}, t=1, \ldots, k\right)$, who are responsible for assessing $m$ alternatives $\left(A_{i}, i=1, \ldots, m\right)$, with respect to the importance of each of the $n$ criteria, $\left(C_{j},=1, \ldots, n\right)$ (Bashiri and Badri, 2011). 
Step 2. Identify appropriate linguistic variables and their positive triangular fuzzy numbers. Linguistic variables are used to calculate the importance weights of criteria and the ratings of the alternatives with respect to distinct criteria. For example, linguistic variable "Very High (VH)" which can be defined by a triangular fuzzy number $(0.75 ; 1 ; 1)$.

Step 3. Construct a fuzzy decision matrix by pulling the decision makers' opinions to get the aggregated fuzzy weight of the criteria, and the aggregated fuzzy rating of alternatives. Let $k$ is the number of decision makers in a group and, the aggregated fuzzy weight $\left(\tilde{w}_{j}\right)$ with respect to each criterion can be calculated as (Chen, 2000):

$$
\tilde{w}_{j}=\frac{1}{k}\left[\tilde{w}_{j 1} \oplus \tilde{w}_{j 2} \oplus \ldots \oplus \tilde{w}_{j k}\right] .
$$

And also the aggregated fuzzy ratings $\left(\tilde{x}_{i j}\right)$ of alternatives with respect to each criterion can be calculated as:

$$
\tilde{x}_{i j}=\frac{1}{k}\left[\tilde{x}_{i j 1} \oplus \tilde{x}_{i j 2} \oplus \ldots \oplus \tilde{x}_{i j k}\right] .
$$

In the supplier selection problem, the value of aggregated weights and ratings are expressed in matrix format as follows:

$$
\tilde{D}=\left[\begin{array}{cccc}
\tilde{x}_{11} & \tilde{x}_{12} & \cdots & \tilde{x}_{1 n} \\
\tilde{x}_{21} & \tilde{x}_{22} & \cdots & \tilde{x}_{2 n} \\
\vdots & \vdots & \cdots & \vdots \\
\tilde{x}_{m 1} & \tilde{x}_{m 2} & \cdots & \tilde{x}_{m n}
\end{array}\right], \tilde{W}=\left[\begin{array}{lll}
\tilde{w}_{1} & \tilde{w}_{2} \cdots & \tilde{w}_{n}
\end{array}\right]
$$

$i=1, \ldots, m$ for alternatives, and $j=1, \ldots, n$,for criteria

Step 4. Defuzzify the fuzzy decision matrix and fuzzy weight of each criterion in to crisp values using the relation $\mathrm{BNP}_{i}$ based on the COA defuzzification method proposed in section 3 (Relation 16).

Step 5. Determine best crisp value $\left(f_{j}^{*}\right)$ and worst crisp value $\left(f_{j}^{-}\right)$for all criterion ratings, $(j=1, \ldots, n)$ by using the relations:

$$
\left(f_{j}^{*}\right)=\max _{i} \tilde{x}_{i j}, \quad\left(f_{j}^{-}\right)=\min _{i} \tilde{x}_{i j},
$$

Step 6. Compute the values $S_{i}$ and $R_{i}$ using the relations (4), (5) respectively.

Step 7. Compute the values $Q_{i}$ using the relation (6) described in section 2.

Step 8. Rank the alternatives by sorting each $S, R$, and $Q$ values in ascending order.

Step 9. Select the best alternatives as a compromise solution by referring step 5 of section 2 .

\section{CASE STUDY}

Supplier selection is an important part of the business as well as a production strategy for industrial organizations. Selection of best supplier enhances the quality and 
economic growth of enterprise but, still it is a difficult task to select an appropriate supplier. Therefore, the proposed model has been used to evaluate and select the most suitable supplier of a computer manufacturing industry in the southern part of India. The proposed supplier selection approach has been made in the following steps:

Step 1. Some key components and accessories of computers have to be purchased for the production of new company products. Therefore, the company needs to select a suitable supplier. There are five suppliers such as, $\mathrm{S}_{1}, \mathrm{~S}_{2}, \mathrm{~S}_{3}, \mathrm{~S}_{4}$, and $\mathrm{S}_{5}$ participating in the selection process. These are the six qualitative criteria used to evaluate the suppliers:

$C_{1}$ : On time delivery of goods,

$C_{3}$ : Response to correspondence,

$C_{2}$ : Quality of products,

$C_{5}$ : Services contract performance,

$C_{4}$ : Flexibility, $C_{6}:$ Cost/Price.

Three decision makers $\mathrm{D}_{1}, \mathrm{D}_{2}$ and $\mathrm{D}_{3}$ have been grouped to resolve the problems of the entire selection process.

Step 2. Decision makers have been using the five linguistic variables for weighting as shown in Figure 2 and also five linguistic variables for rating of suppliers which are shown in Figure 3. The corresponding fuzzy numbers of linguistic variables for weights and ratings are shown in Table 1 and Table 2, respectively. Then, the decision makers use the linguistic weighting variables to assess the importance weight of each criterion as shown in Table 3. Also, they have used the linguistic ratings to rate the alternatives presented in Table 4 . Next, the calculated fuzzy numbers of importance weights and ratings are tabulated in Table 5 and 6 , respectively.

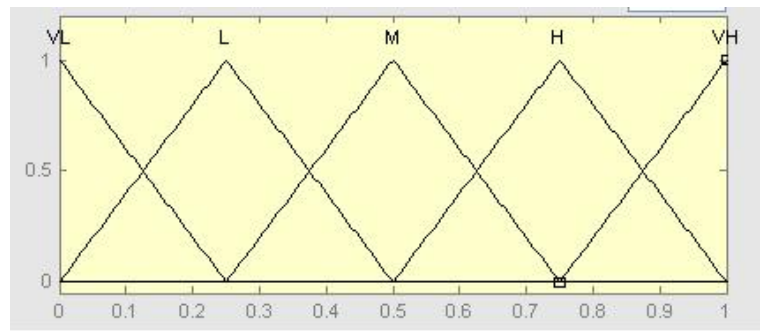

Fig. 2. Linguistic variables for importance weight of each criteria.

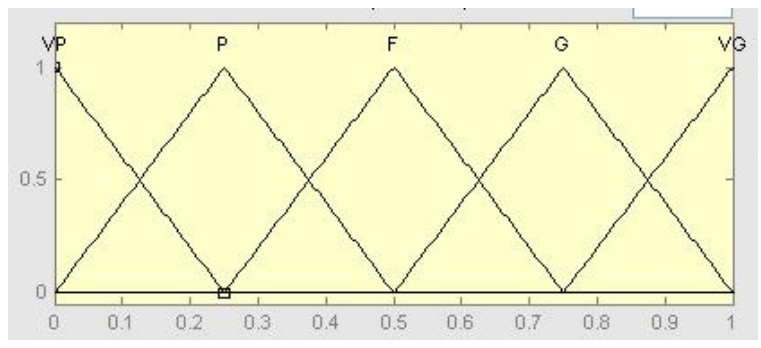

Fig. 3. Linguistic variables for ratings. 
Table 1. Linguistic variables for weights.

\begin{tabular}{|c|c|}
\hline Very Low $(\mathrm{VL})$ & $(0,0,0.25)$ \\
\hline Low $(\mathrm{L})$ & $(0,0.25,0.5)$ \\
\hline Medium $(\mathrm{M})$ & $(0.25,0.5,0.75)$ \\
\hline High $(\mathrm{H})$ & $(0.5,0.75,1)$ \\
\hline Very High $(\mathrm{VH})$ & $(0.75,1,1)$ \\
\hline
\end{tabular}

Table 2. Linguistic variables for ratings.

\begin{tabular}{|c|c|}
\hline Very Poor (VP) & $(0,0,0.25)$ \\
\hline Poor $(\mathrm{P})$ & $(0,0.25,0.5)$ \\
\hline Fair $(\mathrm{F})$ & $(0.25,0.5,0.75)$ \\
\hline Good $(\mathrm{G})$ & $(0.5,0.75,1)$ \\
\hline Very Good $(\mathrm{VG})$ & $(0.75,1,1)$ \\
\hline
\end{tabular}

Table 3. Importance weight of criteria from three decision makers.

\begin{tabular}{cccc}
\hline Criteria & \multicolumn{3}{c}{ Decision makers (DMs). } \\
& $\mathrm{D}_{1}$ & $\mathrm{D}_{2}$ & $\mathrm{D}_{3}$ \\
\hline $\mathrm{C}_{1}$ & $\mathrm{VH}$ & $\mathrm{H}$ & $\mathrm{VH}$ \\
$\mathrm{C}_{2}$ & $\mathrm{H}$ & $\mathrm{VH}$ & $\mathrm{H}$ \\
$\mathrm{C}_{3}$ & $\mathrm{M}$ & $\mathrm{VH}$ & $\mathrm{VH}$ \\
$\mathrm{C}_{4}$ & $\mathrm{VH}$ & $\mathrm{M}$ & $\mathrm{M}$ \\
$\mathrm{C}_{5}$ & $\mathrm{H}$ & $\mathrm{M}$ & $\mathrm{H}$ \\
$\mathrm{C}_{6}$ & $\mathrm{VH}$ & $\mathrm{VH}$ & $\mathrm{VH}$ \\
\hline
\end{tabular}

Table 4. Ratings of five suppliers under each criterion in terms of linguistic variables determined by DMs.

\begin{tabular}{cccccccc}
\hline DMs & Suppliers & \multicolumn{7}{c}{ Criteria } \\
& & $\mathrm{C}_{1}$ & $\mathrm{C}_{2}$ & $\mathrm{C}_{3}$ & $\mathrm{C}_{4}$ & $\mathrm{C}_{5}$ & $\mathrm{C}_{6}$ \\
\hline $\mathrm{D}_{1}$ & $\mathrm{~S}_{1}$ & $\mathrm{~F}$ & $\mathrm{VG}$ & $\mathrm{F}$ & $\mathrm{G}$ & $\mathrm{G}$ & $\mathrm{VG}$ \\
& $\mathrm{S}_{2}$ & $\mathrm{G}$ & $\mathrm{VG}$ & $\mathrm{G}$ & $\mathrm{F}$ & $\mathrm{G}$ & $\mathrm{VG}$ \\
& $\mathrm{S}_{3}$ & $\mathrm{VG}$ & $\mathrm{G}$ & $\mathrm{F}$ & $\mathrm{G}$ & $\mathrm{F}$ & $\mathrm{F}$ \\
& $\mathrm{S}_{4}$ & $\mathrm{VG}$ & $\mathrm{F}$ & $\mathrm{G}$ & $\mathrm{G}$ & $\mathrm{P}$ & $\mathrm{VG}$ \\
& $\mathrm{S}_{5}$ & $\mathrm{VG}$ & $\mathrm{G}$ & $\mathrm{F}$ & $\mathrm{F}$ & $\mathrm{G}$ & $\mathrm{G}$ \\
\hline $\mathrm{D}_{2}$ & $\mathrm{~S}_{1}$ & $\mathrm{G}$ & $\mathrm{F}$ & $\mathrm{F}$ & $\mathrm{F}$ & $\mathrm{G}$ & $\mathrm{G}$ \\
& $\mathrm{S}_{2}$ & $\mathrm{~F}$ & $\mathrm{VG}$ & $\mathrm{F}$ & $\mathrm{G}$ & $\mathrm{G}$ & $\mathrm{G}$ \\
& $\mathrm{S}_{3}$ & $\mathrm{~F}$ & $\mathrm{G}$ & $\mathrm{G}$ & $\mathrm{VG}$ & $\mathrm{F}$ & $\mathrm{VG}$ \\
& $\mathrm{S}_{4}$ & $\mathrm{VG}$ & $\mathrm{G}$ & $\mathrm{F}$ & $\mathrm{G}$ & $\mathrm{G}$ & $\mathrm{VG}$ \\
& $\mathrm{S}_{5}$ & $\mathrm{~F}$ & $\mathrm{G}$ & $\mathrm{F}$ & $\mathrm{G}$ & $\mathrm{VG}$ & $\mathrm{VG}$ \\
\hline $\mathrm{D}_{3}$ & $\mathrm{~S}_{1}$ & $\mathrm{~F}$ & $\mathrm{G}$ & $\mathrm{F}$ & $\mathrm{G}$ & $\mathrm{VG}$ & $\mathrm{VG}$ \\
& $\mathrm{S}_{2}$ & $\mathrm{VG}$ & $\mathrm{G}$ & $\mathrm{G}$ & $\mathrm{F}$ & $\mathrm{F}$ & $\mathrm{F}$ \\
& $\mathrm{S}_{3}$ & $\mathrm{~F}$ & $\mathrm{~F}$ & $\mathrm{VG}$ & $\mathrm{G}$ & $\mathrm{G}$ & $\mathrm{G}$ \\
& $\mathrm{S}_{4}$ & $\mathrm{G}$ & $\mathrm{F}$ & $\mathrm{G}$ & $\mathrm{G}$ & $\mathrm{P}$ & $\mathrm{F}$ \\
& $\mathrm{S}_{5}$ & $\mathrm{VG}$ & $\mathrm{VG}$ & $\mathrm{G}$ & $\mathrm{G}$ & $\mathrm{F}$ & $\mathrm{G}$ \\
\hline
\end{tabular}


Table 5. Importance weights of criteria in terms of fuzzy numbers for each criterion.

\begin{tabular}{|c|c|c|c|c|c|}
\hline $\mathrm{C}_{1}$ & $\mathrm{C}_{2}$ & $\mathrm{C}_{3}$ & $\mathrm{C}_{4}$ & $\mathrm{C}_{5}$ & $\mathrm{C}_{6}$ \\
\hline $\mathrm{D}_{1}(0.75,1.00,1.00)$ & $(0.50,0.75,1.00)$ & $(0.25,0.50,0.75)$ & $(0.75,1.00,1.00)$ & $(0.50,0.75,1.00)$ & $(0.75,1.00,1.00)$ \\
\hline $\mathrm{D}_{2}(0.50,0.75,1.00)$ & $(0.75,1.00,1.00)$ & $(0.75,1.00,1.00)$ & $(0.25,0.50,0.75)$ & $(0.25,0.50,0.75)$ & $(0.75,1.00,1.00)$ \\
\hline $\mathrm{D}_{3}(0.75,1.00,1.00)$ & $(0.50,0.75,1.00)$ & $(0.75,1.00,1.00)$ & $(0.25,0.50,0.75)$ & $(0.50,0.75,1.00)$ & $(0.75,1.00,1.00)$ \\
\hline
\end{tabular}

Table 6. Rating of each supplier under each criterion in terms of fuzzy numbers.

\begin{tabular}{|c|c|c|c|c|c|c|}
\hline \multirow{2}{*}{$\begin{array}{l}\text { Supplier } \\
\text { Criteria }\end{array}$} & \multicolumn{6}{|c|}{$\mathrm{S}_{1}$} \\
\hline & $\mathrm{C}_{1}$ & $\mathrm{C}_{2}$ & $\mathrm{C}_{3}$ & $\mathrm{C}_{4}$ & $\mathrm{C}_{5}$ & $\mathrm{C}_{6}$ \\
\hline $\mathrm{D}_{1}$ & $(0.25,0.50,0.75)$ & $(0.75,1.00,1.00)$ & $(0.25,0.5,0.75)$ & $(0.50,0.75,1.00)$ & $(0.50,0.75,1.00)$ & $(0.75,1.00,1.00)$ \\
\hline $\mathrm{D}_{2}$ & $(0.50,0.75,1.00)$ & $(0.25,0.50,0.75)$ & $(0.25,0.5,0.75)$ & $(0.25,0.50,0.75)$ & $(0.50,0.75,1.00)$ & $(0.50,0.75,1.00)$ \\
\hline \multirow[t]{2}{*}{$\mathrm{D}_{3}$} & $(0.25,0.50,0.75)$ & $(0.50,0.75,1.00)$ & $(0.25,0.5,0.75)$ & $(0.50,0.75,1.00)$ & $(0.75,1.00,1.00)$ & $(0.75,1.00,1.00)$ \\
\hline & \multicolumn{6}{|c|}{$\mathrm{S}_{2}$} \\
\hline $\mathrm{D}_{1}$ & $(0.50,0.75,1.00)$ & $(0.75,1.00,1.00)$ & $(0.50,0.75,1.00)$ & $(0.25,0.50,0.75)$ & $(0.50,0.75,1.00)$ & $(0.75,1.00,1.00)$ \\
\hline $\mathrm{D}_{2}$ & $(0.25,0.50,0.75)$ & $(0.75,1.00,1.00)$ & $(0.25,0.50,0.75)$ & $(0.50,0.75,1.00)$ & $(0.50,0.75,1.00)$ & $(0.50,0.75,1.00)$ \\
\hline \multirow[t]{2}{*}{$\mathrm{D}_{3}$} & $(0.75,1.00,1.00)$ & $(0.50,0.75,1.00)$ & $(0.50,0.75,1.00)$ & $(0.25,0.50,0.75)$ & $(0.25,0.50,0.75)$ & $(0.25,0.50,0.75)$ \\
\hline & \multicolumn{6}{|c|}{$\mathrm{S}_{3}$} \\
\hline $\mathrm{D}_{1}$ & $(0.75,1.00,1.00)$ & $(0.50,0.75,1.00)$ & $(0.25,0.50,0.75)$ & $(0.50,0.75,1.00)$ & $(0.25,0.50,0.75)$ & $(0.25,0.50,0.75)$ \\
\hline $\mathrm{D}_{2}$ & $(0.25,0.50,0.75)$ & $(0.50,0.75,1.00)$ & $(0.50,0.75,1.00)$ & $(0.75,1.00,1.00)$ & $(0.25,0.50,0.75)$ & $(0.75,1.00,1.00)$ \\
\hline \multirow[t]{2}{*}{$\mathrm{D}_{3}$} & $(0.25,0.50,0.75)$ & $(0.25,0.50,0.75)$ & $(0.75,1.00,1.00)$ & $(0.50,0.75,1.00)$ & $(0.50,0.75,1.00)$ & $(0.50,0.75,1.00)$ \\
\hline & \multicolumn{6}{|c|}{$\mathrm{S}_{4}$} \\
\hline $\mathrm{D}_{1}$ & $(0.75,1.00,1.00)$ & $(0.25,0.50,0.75)$ & $(0.50,0.75,1.00)$ & $(0.50,0.75,1.00)$ & $(0.00,0.25,0.50)$ & $(0.75,1.00,1.00)$ \\
\hline $\mathrm{D}_{2}$ & $(0.75,1.00,1.00)$ & $(0.50,0.75,1.00)$ & $(0.25,0.50,0.75)$ & $(0.50,0.75,1.00)$ & $(0.50,0.75,1.00)$ & $(0.75,1.00,1.00)$ \\
\hline \multirow[t]{2}{*}{$\mathrm{D}_{3}$} & $(0.50,0.75,1.00)$ & $(0.25,0.50,0.75)$ & $(0.5,0.75,1.00)$ & $(0.50,0.75,1.00)$ & $(0.00,0.25,0.50)$ & $(0.25,0.50,0.75)$ \\
\hline & \multicolumn{6}{|c|}{$\mathrm{S}_{5}$} \\
\hline $\mathrm{D}_{1}$ & $(0.75,1.00,1.00)$ & $(0.50,0.75,1.00)$ & $(0.25,0.50,0.75)$ & $(0.25,0.50,0.75)$ & $(0.50,0.75,1.00)$ & $(0.50,0.75,1.00)$ \\
\hline $\mathrm{D}_{2}$ & $(0.25,0.50,0.75)$ & $(0.50,0.75,1.00)$ & $(0.25,0.50,0.75)$ & $(0.50,0.75,1.00)$ & $(0.75,1.00,1.00)$ & $(0.75,1.00,1.00)$ \\
\hline $\mathrm{D}_{3}$ & $(0.75,1.00,1.00)$ & $(0.75,1.00,1.00)$ & $(0.50,0.75,1.00)$ & $(0.50,0.75,1.00)$ & $(0.25,0.50,0.75)$ & $(0.50,0.75,1.00)$ \\
\hline
\end{tabular}


Step 3. The aggregated fuzzy weight $\left(\tilde{w}_{j}\right)$ of each criterion and aggregated fuzzy ratings $\left(\tilde{x}_{i j}\right)$ of each criterion with respect to the suppliers are calculated by using the relation (17) and (18), respectively. Then, construct a fuzzy decision matrix by putting these aforesaid data and shown in Table 7 .

Table 7. Fuzzy decision matrix.

\begin{tabular}{|c|c|c|c|c|c|c|}
\hline & \multicolumn{6}{|c|}{ Criteria. } \\
\hline & $\mathrm{C}_{1}$ & $\mathrm{C}_{2}$ & $\mathrm{C}_{3}$ & $\mathrm{C}_{4}$ & $\mathrm{C}_{5}$ & $\mathrm{C}_{6}$ \\
\hline Weight & $(0.67,0.92,1.00)$ & $(0.58,0.83,1.00)$ & $(0.58,0.83,0.92)$ & $(0.42,0.67,0.83)$ & $(0.42,0.67,0.92)$ & $(0.75,1.00,1.00)$ \\
\hline $\mathrm{S}_{1}$ & $(0.33,0.58,0.83)$ & $(0.50,0.75,0.92)$ & $(0.25,0.50,0.75)$ & $(0.42,0.67,0.92)$ & $(0.58,0.83,1.00)$ & $(0.67,0.92,1.00)$ \\
\hline $\mathrm{S}_{2}$ & $(0.50,0.75,0.92)$ & $(0.67,0.92,1.00)$ & $(0.42,0.67,0.92)$ & $(0.33,0.58,0.83)$ & $(0.42,0.67,0.92)$ & $(0.50,0.75,0.92)$ \\
\hline $\mathrm{S}_{3}$ & $(0.42,0.67,0.83)$ & $(0.42,0.67,0.92)$ & $(0.50,0.75,0.92)$ & $(0.58,0.83,1.00)$ & $(0.33,0.58,0.83)$ & $(0.50,0.75,0.92)$ \\
\hline $\mathrm{S}_{4}$ & $(0.67,0.92,1.00)$ & $(0.33,0.58,0.83)$ & $(0.42,0.67,0.92)$ & $(0.50,0.75,1.00)$ & $(0.16,0.42,0.67)$ & $(0.58,0.83,0.92)$ \\
\hline $\mathrm{S}_{5}$ & $(0.58,0.83,0.92)$ & $(0.58,0.83,1.00)$ & $(0.33,0.58,0.83)$ & $(0.42,0.67,0.92)$ & $(0.50,0.75,0.92)$ & $(0.58,0.83,1.00)$ \\
\hline
\end{tabular}

Step 4. Compute the crisp values of decision matrix and weight of each criterion and presented in Table 8.

Table 8. Crisp values for decision matrix and weight of each criterion.

\begin{tabular}{ccccccc}
\hline & \multicolumn{7}{c}{ Criteria } \\
& $\mathrm{C}_{1}$ & $\mathrm{C}_{2}$ & $\mathrm{C}_{3}$ & $\mathrm{C}_{4}$ & $\mathrm{C}_{5}$ & $\mathrm{C}_{6}$ \\
\hline Weight & 0.86 & 0.80 & 0.78 & 0.64 & 0.67 & 0.92 \\
$\mathrm{~S}_{1}$ & 0.58 & 0.72 & 0.50 & 0.67 & 0.80 & 0.86 \\
$\mathrm{~S}_{2}$ & 0.72 & 0.86 & 0.67 & 0.58 & 0.67 & 0.72 \\
$\mathrm{~S}_{3}$ & 0.64 & 0.67 & 0.72 & 0.80 & 0.58 & 0.72 \\
$\mathrm{~S}_{4}$ & 0.86 & 0.58 & 0.67 & 0.75 & 0.42 & 0.78 \\
$\mathrm{~S}_{5}$ & 0.78 & 0.80 & 0.58 & 0.67 & 0.72 & 0.80 \\
\hline
\end{tabular}

Step 5. These are the best and worst values of all criterion ratings listed below:

$$
\begin{aligned}
& f_{1}^{*}=0.86, f_{2}^{*}=0.86, f_{3}^{*}=0.72, f_{4}^{*}=0.80, f_{5}^{*}=0.80, f_{6}^{*}=0.86 \\
& f_{1}^{-}=0.58, f_{2}^{-}=0.58, f_{3}^{-}=0.50, f_{4}^{-}=0.58, f_{5}^{-}=0.42, f_{6}^{-}=0.72
\end{aligned}
$$

Step 6. Compute the values of S, R and Q for all suppliers and presented in Table 9.

Step 7. Ranking of suppliers by S, R and Q in ascending order are shown in Table 10. 
Table 9. The values of $S, R$ and $Q$ for all suppliers.

\begin{tabular}{cccccc}
\hline \multicolumn{5}{c}{ Suppliers } \\
\hline & $\mathrm{S}_{1}$ & $\mathrm{~S}_{2}$ & $\mathrm{~S}_{3}$ & $\mathrm{~S}_{4}$ & $\mathrm{~S}_{5}$ \\
\hline $\mathrm{S}$ & 2.42 & 2.40 & 2.52 & 2.32 & 1.83 \\
$\mathrm{R}$ & 0.86 & 0.92 & 0.92 & 0.80 & 0.39 \\
$\mathrm{Q}$ & 0.87 & 0.91 & 1.00 & 0.74 & 0.00 \\
\hline
\end{tabular}

Table 10. The ranking of the suppliers by $S, R$ and $Q$ in ascending order.

\begin{tabular}{cccccc}
\hline & \multicolumn{5}{c}{ Ranking suppliers } \\
\hline & 1 & 2 & 3 & 4 & 5 \\
\hline By S & $\mathrm{S}_{5}$ & $\mathrm{~S}_{4}$ & $\mathrm{~S}_{2}$ & $\mathrm{~S}_{1}$ & $\mathrm{~S}_{3}$ \\
By R & $\mathrm{S}_{5}$ & $\mathrm{~S}_{4}$ & $\mathrm{~S}_{1}$ & $\mathrm{~S}_{2}$ & $\mathrm{~S}_{3}$ \\
By Q & $\mathrm{S}_{5}$ & $\mathrm{~S}_{4}$ & $\mathrm{~S}_{1}$ & $\mathrm{~S}_{2}$ & $\mathrm{~S}_{3}$ \\
\hline
\end{tabular}

Step 8. From Table 9, it has been shown that the suppliers $\mathrm{S}_{5}$ is best ranked by $\mathrm{Q}$ and also both $\mathrm{C}_{1}$ and $\mathrm{C}_{2}$ conditions are satisfied, means $\left(Q_{S 4}-Q_{S 5}\right) \geqslant \frac{1}{(5-1)}$ and $\mathrm{S}_{5}$ is best ranked by $\mathrm{R}$ and $\mathrm{S}$ also. Therefore, $\mathrm{S}_{5}$ is the best selected supplier for the best compromise solution.

\section{CONCLUSION}

Supplier selection is a part of supply chain management which is used in the upstream of the production process and affecting all the areas of an organization. In this paper an efficient method has been proposed to solve the supplier selection problem and select the best supplier through a multi criteria group decision making process under a fuzzy environment. In a decision making process, the decision makers are unable to express their opinions exactly in numerical values due to imprecision in the subjective judgment of decision-makers. In order to deal with such problems fuzzy set theory has been implemented and the evaluations are expressed in linguistic terms. In this research a new MDCM approach, VIKOR under a fuzzy environment has been implemented to deal with both qualitative and quantitative criteria and a suitable supplier has been selected successfully. The outranking order of suppliers and rating of suppliers can easily be determined by using this method. Finally, the proposed method has been seemed simple, flexible and systematic approach and can be applied in different types of decision making problems.

\section{ACKNOWLEDGEMENTS}

The author takes the prerogative through this opportunity to express his sincere thanks and gratitude to the Chief Editor, Prof. Kaczmarczyk, and learned reviewers for their valuable comments and suggestions for the improvement and betterment of this paper. 


\section{REFERENCES}

Altinoz, C. \& Winchester, S.C. (2001). A Fuzzy Approach to Supplier Selection. Journal of Textile Institute 92(2), 155-167.

Bashiri, M. \& Badri, H. (2011), A group decision making procedure for fuzzy interactive linear assignment programming, Expert Syst. Appl. 38(5), 5561-5568.

Chang, C.-L. (2010), A modified vikor method for multiple criteria analysis, Environmental Monitoring and Assessment 168, 339-344.

Chen, C.-T. (2000), Extensions of the topsis for group decision-making under fuzzy environment, Fuzzy Sets and Systems 114(1), 1-9.

Ghodsypour, S. \& OBrien, C. (1998), A decision support system for supplier selection using an integrated analytic hierarchy process and linear programming, International Journal of Production Economics 56-57(1), 199-212.

Huang, J.J., Tzeng, G.H., \& Liu, H.H. (2009), A Revised VIKOR Model for Multiple Criteria Decision Making - The Perspective of Regret Theory, in Y. Shi et al. (Eds.) MCDM 2009, Communications in Computer and Information Science 35(1), 761-768, Springer-Verlag Berlin Heidelberg.

Kubat, C., \& Yuce, B. (2006), Supplier Selection with Genetic Algorithm and Fuzzy AHP, Proceedings of 5th International Symposium on Intelligent Manufacturing Systems, May 29-31, 1382-1401.

Kumar, M., Vrat, P. \& Shankar, R. (2004), A fuzzy goal programming approach for vendor selection problem in a supply chain, Comput. Ind. Eng. 46(1), 69-85.

Kuo, M.-S. \& Liang, G.-S. (2011), Combining vikor with gra techniques to evaluate service quality of airports under fuzzy environment, Expert Syst. Appl. 38(3), 1304-1312.

Moeinzadeh, P. \& Hajfathaliha, A. (2010), A combined fuzzy decision making approach to supply chain risk assessment, International Journal of Human and Social Sciences 5(13), 859-875.

Opricovic, S. (1998), Multi-criteria optimization of civil engineering systems, Faculty of Civil Engineering, Belgrade.

Opricovic, S. \& Tzeng, G.-H. (2004), Compromise solution by mcdm methods: A comparative analysis of vikor and topsis, European Journal of Operational Research 156(2), 445-455.

Opricovic, S. \& Tzeng, G.-H. (2007), Extended vikor method in comparison with outranking methods, European Journal of Operational Research 178(2), 514-529.

Park, J. H., Cho, H. J. \& Kwun, Y. C. (2011), Extension of the vikor method for group decision making with interval-valued intuitionistic fuzzy information, Fuzzy Optimization and Decision Making 10(3), 233-253.

Roodhooft, F. \& Konings, J. (1997), Vendor selection and evaluation an activity based costing approach, European Journal of Operational Research 96(1), 97-102.

Saghafian, S. \& Hejazi, S. R. (2005), Multi-criteria group decision making using a modified fuzzy topsis procedure, in Proceedings of the International Conference on Computational Intelligence for Modelling, Control and Automation and International Conference on Intelligent Agents, Web Technologies and Internet Commerce Vol-2 (CIMCA-IAWTIC06) - Volume 02, CIMCA 05, IEEE Computer Society, Washington, DC, USA, 215-221.

Sanayei, A., Farid Mousavi, S. \& Yazdankhah, A. (2010), Group decision making process for supplier selection with vikor under fuzzy environment, Expert Systems with Applications 37(1), 24-30.

Sanayei, A., Mousavi, S. F., Abdi, M. \& Mohaghar, A. (2008), An integrated group decisionmaking process for supplier selection and order allocation using multi-attribute utility theory and linear programming, Journal of the Franklin Institute 345(7), 731-747. 
Shahanaghi, K., Yazdian, S. A. (2009), Vendor Selection Using a New Fuzzy Group TOPSIS Approach, Journal of Uncertain Systems 3(3), 221-231.

Tsai, C.H., Chang, C.L., \& Chen, L. (2003), Applying Grey Relational Analysis to the Vendor Evaluation Model, International Journal of the Computer, the Internet and Management 11(3), 45-53.

Weber, C. A., Current, J. R. \& Desai, A. (1998), Non-cooperative negotiation strategies for vendor selection, European Journal of Operational Research 108(1), 208-223.

Wu, M., Liu, Z. J. (2011), The supplier selection application based on two methods: VIKOR algorithm with entropy method and Fuzzy TOPSIS with vague sets method, International Journal of Management Science and Engineering Management 6(2), 936-946.

$\mathrm{Yu}, \mathrm{P}$. (1973), A class of solutions for group decision problems, Management Science 19(8), 936-946.

Zadeh, L. (1965), Fuzzy sets, Information and Control 8(3), 338-353.

Zadeh, L. (1975), The concept of a linguistic variable and its application to approximate reasoning, Information Sciences 8(3), 199-249. 